\title{
Applying a resource model of stress to the cancer caregiver experience
}

\author{
Tony Cassidy ,' Marian McLaughlin, Melanie Giles \\ School of Psychology, University of Ulster, Ireland
}

Received: November 1, 2013

Accepted: December 21, 2014 Online Published: January 14, 2015

DOI: $10.5430 /$ cns.v3n2p59

URL: http://dx.doi.org/10.5430/cns.v3n2p59

\begin{abstract}
Objectives: The aim of this study was to apply a resource model of stress and coping to explaining the relationship between burden of care, perceived stress, optimism, resilience, self-efficacy, perceived support and psychological distress, and to test the role of satisfaction with medical care in the process.

Methods: A cross-sectional survey using questionnaire measures was conducted with a group of 269 female cancer caregivers who were caring for a spouse, a parent or a child with cancer. Participants were accessed via an oncology clinic.

Results: Analysis supported the resource model showing that psychological resources and social support mediate the impact of burden of care on caregiver mental health. Satisfaction with medical care added to the explanatory power of the model.

Conclusions: This study provides support for a resource model of stress and the potential utility of resource building interventions in terms of increased social support and the development of psychological resources such as resilience skills. In addition it points to the importance of positive experience of health care services for caregivers and suggests that this may be a fruitful way to improve their quality of life.
\end{abstract}

Key Words: Cancer, Oncology, Caregiver, Stress, Burden, Resource model

\section{Introduction}

Research on caregiving has tended to adopt a pathological approach based on a literature that has largely shown that caregiving is a negative experience and has damaging effects on the health of caregivers. ${ }^{[1]}$ This has underestimated the strengths and resources of caregivers and through a focus on ill health effects has ignored opportunities to prevent ill effects and build positive health. ${ }^{[2]}$ The current research attempts to address this by focusing on the strengths and resources of care givers which might negate the negative effects of the care giving role.

One widely used theoretical model in researching the impact of caregiving is the transactional model of stress. ${ }^{[3]}$ In this model stress is seen as a transaction between the person and their environment in which demands of life (stressors) exert an impact on the health and wellbeing of the person. ${ }^{[4]}$ The impact of demands are in turn mediated or moderated by the individual's appraisal and coping responses. The model has generally been applied as a deficit model focusing on negative outcomes determined by deficits in coping skills.

Since the turn of the century the development of positive psychology has led to more of a focus on social and psychological resources and how these might mediate the impact of stress. ${ }^{[4]}$ Social resources focus on social support, while

*Correspondence: Tony Cassidy; Email: t.cassidy@ulster.ac.uk; Address: School of Psychology, University of Ulster, Cromore Road, Coleraine, N. Ireland.

Published by Sciedu Press 
psychological resources are include self-efficacy, optimism and resilience. ${ }^{[4]}$ The identification of social and psychological resources presents an opportunity to utilise them in a revised resorce model of stress and coping such as that presented in Figure 1.

A substantial literature attests to the stress of informal caregiving and its impact on both mental and physical health, ${ }^{[5-7]}$ with female caregivers experiencing more stress than male caregivers. ${ }^{[8-10]}$ Applying the stress model to care giving would predict a correlation between the burden of caring and psychological distress.

The emergence of a positive health psychology ${ }^{[11]}$ inspires a philosophy that suggests we can learn more from what makes people well than what makes them ill and encourages a move away from the deficit model of stress to a resource model. The established psychological resources of resilience, optimism, and self-efficacy, and the social resources of support from friends and family ${ }^{[2]}$ enable the development of such a resource model as shown in Figure 1.

As well as being well established as mediators in the general stress and health literature ${ }^{[2]}$ each of resilience, ${ }^{[12]}$ selfefficacy, ${ }^{[13]}$ optimism, ${ }^{[14]}$ and social support ${ }^{[15]}$ have been shown to mediate the impact of stress on health in caregivers. The emergence of a positive health focus has also paved the way for a growth in resilience building approaches to stress and health interventions ${ }^{[16]}$ in both individuals and families. ${ }^{[17]}$ Applying a resource model to caregiving will inform decisions about the efficacy of resilience building as an intervention.

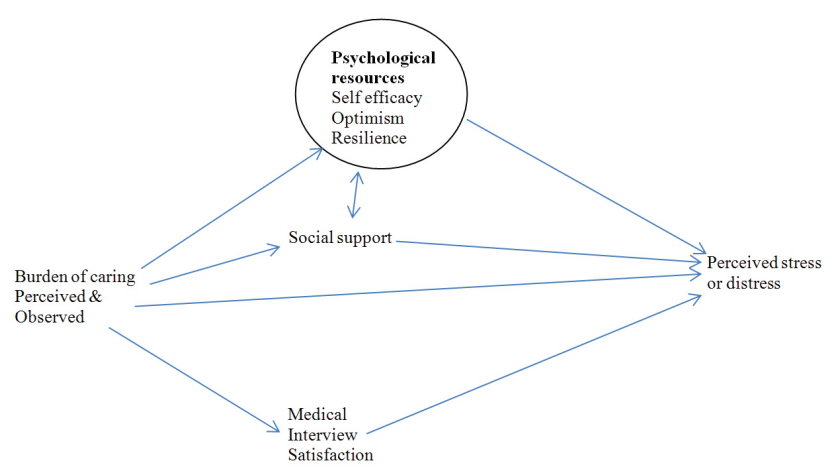

Figure 1: Proposed caregiver resource model based on extended modified stress-coping model

Satisfaction with medical care has been widely researched and shown to reduce negative effects in regard to patients with chronic illness ${ }^{[18-20]}$ but the role of satisfaction with medical care has been largely neglected in regard to their caregivers. The relationship with health care professionals, in particular the level of satisfaction with information provided and communication with medical personnel, has been shown to mediate the stress of chronic illness ${ }^{[15-17]}$ and is likely to also impact on the stress experienced by caregivers.
With caregivers increasingly playing a central role in health care delivery the coordination between professional and informal caregivers becomes ever more important. ${ }^{[21]}$ Satisfaction with medical care is likely to be a resource in informal caregiving and makes a useful addition to a resource model of stress in this area.

The current study proposes to apply a resource model of stress and coping (see Figure 1) to explaining the relationship between burden of care, perceived stress, optimism, resilience, self-efficacy, perceived support and psychological distress, and to test the role of satisfaction with medical care in the process.

\section{Method}

A cross-sectional survey design with questionnaire data collection was used to test the efficacy of a resource model of stress and copy in explaining the relationship between burden of care, perceived stress, optimism, resilience, selfefficacy, perceived support and psychological distress, and to test the role of satisfaction with medical care in the process.

\subsection{Participants}

Permission was obtained from 4 hospitals in the UK to visit oncology departments and leave questionnaires in return envelopes for those using the clinics. It was clearly indicated that these were for caregivers only and not for patients. Inclusion criteria were that participants were caregivers for a relative with cancer, and were not themselves patients. Those who were patients were excluded. Initially 100 questionnaire packs were provided to each of the 4 institutions. On request a further 25 packs were provided bringing the total distributed to 500 packs. It was not intended to select a female only sample but only 4 male caregivers responded and these were removed leaving a total sample of $269 \mathrm{fe}-$ males. These female family care givers were the primary caregiver for a relative with cancer.

\subsection{Measures}

The pack comprised a demographics section and the measures listed below. The demographic section asked about age, education, who the care recipient was in relation to the caregiver, how long it was since the care recipient had been diagnosed with their illness, and how long they had been caring for their relative. All participants had been caring for their relative since their initial diagnosis.

Burden and perceived burden (see Table 1). This was measured using a list of 19 tasks ranging from physical aid (lifting, helping to walk) through intimate personal care (bathing, washing, toileting) to emotional care (comforting, dealing with emotional outbursts). The list was derived from structured interviews used in other studies and from discussions of caring tasks with carers. ${ }^{[22]}$ The list was presented 
with two response sets. Firstly participants were asked to rate on a three point scale (never, sometimes, always) how often they carried out each task, and secondly to rate on a four point scale (not at all to extremely) how stressed they felt when carrying out each task. ${ }^{[22-24]}$ This allowed two measures to be produced, burden $(\alpha=.78)$ and perceived burden $(\alpha=.87)$.

Table 1: Caregiving burden scale

\begin{tabular}{|c|c|c|c|c|c|c|c|}
\hline \multirow{2}{*}{$\begin{array}{l}\text { Below are a list of tasks that you might do as a carer for } \\
\text { the person for whom you care. Please rate it. }\end{array}$} & \multicolumn{3}{|c|}{ How often do you do this? } & \multicolumn{4}{|c|}{ How stressed do you feel when doing this? } \\
\hline & Never & Sometimes & Always & Not at all & A little bit & Quite & Extremely \\
\hline \multicolumn{8}{|l|}{ Feeding them } \\
\hline \multicolumn{8}{|l|}{ Bathing or showering them } \\
\hline \multicolumn{8}{|l|}{ Dressing them } \\
\hline \multicolumn{8}{|l|}{ Lifting them in and out of bed } \\
\hline \multicolumn{8}{|l|}{ Taking them to the bathroom or other toileting } \\
\hline \multicolumn{8}{|l|}{ Changing nappies or other continence care } \\
\hline \multicolumn{8}{|l|}{ Organizing help from others } \\
\hline \multicolumn{8}{|l|}{ Organizing appointments } \\
\hline \multicolumn{8}{|l|}{ Organizing transportation to and from appointments } \\
\hline \multicolumn{8}{|l|}{ Dealing with health professionals (eg. GP, doctors) } \\
\hline \multicolumn{8}{|l|}{ Providing emotional support } \\
\hline \multicolumn{8}{|l|}{ Shopping for groceries, preparing meals } \\
\hline \multicolumn{8}{|l|}{ Keeping company, doing activities, reading, playing games } \\
\hline \multicolumn{8}{|l|}{ Bandaging, assisting with oxygen or other equipment } \\
\hline \multicolumn{8}{|l|}{ Administering medication } \\
\hline \multicolumn{8}{|l|}{ Providing comfort when they are distressed } \\
\hline Dealing with mood swings or anger outbursts & & & & & & & \\
\hline
\end{tabular}

The perceived stress scale - 10 item version ${ }^{[25]}$ was developed to assess levels of perceived general stress and is available in 14 item, 10 item and 4 item versions. ${ }^{[26]}$ In this study we used the 10 item version. It contains items which assess how uncontrollable, unpredictable, and overloading one's general life experiences appear and was based on Lazarus's theory of stress appraisal. ${ }^{[27]}$ An example of an item is "How often have you felt that you were unable to control important things in your life?" An acceptable internal reliability score was observed in this study $(\alpha=.86)$.

The generalized self-efficacy scale (GSES) ${ }^{[28]}$ is a 10 item scale developed to assess the construct of self-efficacy. High scores on the scale evidence a positive belief in one's ability to deal with events in life effectively. Items such as "I am confident that I could deal efficiently with unexpected events" reflect confidence in coping ability. In the current study internal consistency was $\alpha=.87$.

The life orientation test (LOT) ${ }^{[29]}$ is a well established measure of optimism and pessimism. In the LOT there are 4 positively worded items which measure optimism (e.g. In uncertain times, I usually expect the best), 4 negatively worded items which measure pessimism (e.g. I hardly ever expect things to go my way), and 4 filler items. Using principal component analysis the scale consistently collapses into two factors reflecting the separate dimensions of optimism, and pessimism. Items are scored on a 5-point Likert scale, ranging from 0 (strongly disagree) to 4 (strongly agree). In this study, internal consistency was $\alpha=.78$ for optimism and $\alpha$ $=.72$ for pessimism.

The brief resilience scale (BRS $)^{[30]}$ is recently developed brief measure of resilience consisting of 6 items which measure the ability to bounce back in adverse situations. Items such as "It does not take me long to recover from a stressful event" are scored on a Likert scale from 1 = strongly disagree to $5=$ strongly agree. Higher scores on the scale indicate more resilience. The measure has been shown to have good validity and reliability. ${ }^{[30]}$ Internal consistency in this study was $\alpha=.83$.

The medical interview satisfaction scale (MISS-21) ${ }^{[31]}$ is a 21 item British version of the original scale devised by Wolf, Putnam, James and Stiles ${ }^{[32]}$ in the USA. It provides a global measure of satisfaction with interactions with health professional. In this study the scale has an overall Cronbach alpha of .92, with individual factor alphas range from .67 to .90 . The scale was devised for use with patients and items were reworded in this study so that they were relevant to a caregiver.

The perceived social support scales (PSS-Fr and PSS-Fa scales). ${ }^{[33]}$ In order to consider support from friends separately to support from family these two 20-item scales were used. The scales are very similar and for the most part vary only in that in one the word "friends" is substituted for the word "family". An example of items would be "My friends 
know how to help me if I'm feeling down" vs. "My friends know how to help me if I'm feeling down". Scoring is on a three-point scale "yes", "no" and "don't know". The scale is designed to measure a different forms of support including, emotional, feedback, informational and giving support. In the current study the reliability coefficient values were friends support $(\alpha=.81)$, and support from family $(\alpha=.83)$.

The general health questionnaire (GHQ-12) ${ }^{[34,35]}$ is frequently used as an epidemiological tool in assessing the prevalence of generalised affective disorder or distress in general populations. In this study we used the 12 item version. Participants are asked to respond to reflect on how they had been feeling over the past month and then respond to statements such as "been feeling unhappy and depressed". The scale can be used with a 4 point Likert scoring format for example by indicating one of the following "not at all", "no more than usual", "rather more than usual" or "much more than usual", scored $0,1,2$ and 3 respectively. The alternative GHQ or clinical method ${ }^{[34,35]}$ uses a score of 0 or 1 where the Likert scores of 0 or 1 are collapsed to 0 and the scores 2 or 3 collapsed to 1 . Using this method a total scale score of 12 is possible where a score above 3 is used to identify caseness (i.e. a distress level that may require clinical intervention). A Cronbach alpha of .87 was obtained in the current study.

\subsection{Procedure}

Ethical approval was received from a University Ethics Committee. Questionnaire packs were left with staff in the reception areas of the clinics. Questionnaire packs were presented in return envelopes with an information sheet attached to the outside of the envelope. The information sheet explained the purpose of the research and that participation was voluntary and without implication for the carer or their patient. Participant's names were not recorded. It also specified that the research was targeting caregivers and the readers were asked to take and pass on additional questionnaires to anyone they knew who was a caregiver for a patient with cancer. Researchers visited the clinics periodically to collect completed questionnaires. Over a period of 10 months 500 questionnaires were provided and a total of 273 were returned completed.

\subsection{Analysis}

The analysis involves presenting descriptive statistics and correlations between variables initially and is followed by exploring the differences across levels of care recipient using analysis of variance. Hierarchical multiple regression analysis (HMRA) is then used to explore relationships with psychological distress that would be predicted by the stress model. This is done controlling for care recipient and producing separate models for those caring for a parent, a child or a spouse.

\section{Results}

In the sample 101 were caring for a spouse, 81 were caring for a child, and 87 were caring for a parent. They ranged in age from 19-74 years with a mean age of 40.8 years, and had been caring for their relative between 3-46 months with a mean of 22.5 months. Informal comments suggested that most participants were quite pleased to be asked to participate and found some satisfaction in being the focus of attention. All participants were female, were the primary caregiver, and had been caring for the care recipient since diagnosis.

Demographics for the sample are shown in Table 2 below. They were all female and 101 were caring for a spouse, 81 were caring for a child, and 87 were caring for a parent. The ranged in age from 19-74 years with a mean age of 40.8 years, and had been caring for their relative between 3-46 months with a mean of 22.5 months. Using the clinical scoring of the GHQ-12 $64.7 \%$ of the total sample were identified as exhibiting symptoms of clinical disorder sufficiently severe to indicate a potential need for intervention.

Table 2: Sample demographics

\begin{tabular}{lll}
\hline Characteristics & Variables & $\mathbf{n}$ \\
\hline Age & $19-34$ & 60 \\
& $31-44$ & 123 \\
& $46-59$ & 66 \\
Care recipient & $60-74$ & 20 \\
& Spouse & 101 \\
& Child & 81 \\
Timeline since & Parent & 87 \\
& $0-6$ months & 67 \\
& $7-12$ months & 52 \\
& 13-24 months & 51 \\
Education & 25 months plus & 99 \\
& Primary & 96 \\
& Secondary & 102 \\
& University & 71 \\
\hline
\end{tabular}

Descriptive statistics and correlations between variables were calculated and are shown in Table 3. Perceived stress correlates statistically significantly with psychological distress $(r=.37, p<.001)$ as measured by the GHQ12, with support from friends $(r=-.24, p<.01)$ but not with support from family, with self efficacy $(r=-.26, p<.01)$, resilience $(r=-.24, p<.01)$, optimism $(r=-.12, p<.05)$, with overall satisfaction with health care $(r=-.14, p<.05)$, with burden of care $(r=.43, p<.001)$ and with perceived burden $(r=$ $.54, p<.001)$. Psychological distress correlates statistically significantly with support from friends $(r=-.34, p<.001)$ and with support from family $(r=-.12, p<.05)$, with selfefficacy $(r=-.51, p<.001)$, resilience $(r=-.50, p<.001)$, optimism $(r=-.26, p<.01)$, with medical interview satisfaction $(r=-.23, p<.01)$, with burden of care $(r=.21, p<$ $.01)$ and with perceived burden $(r=.19, p<.01)$. 
The aim of this study was to test the resource model of stress shown in Figure 1. In order to do this HMRA was used with psychological distress as the dependent variable. The results are shown in Table 4.

In the analysis, burden and perceived burden were entered on step 1 as the stress model would suggest there would be a direct relationship between these variables and the outcome measure of psychological distress. The psychological variables of resilience, optimism, and self efficacy were entered on step 2 as the model would suggest they would be cor- related with the outcome variable of psychological distress and might also reduce the impact of burden and perceived burden. Support from friends and family were entered on step 3 as the model would predict that they would also correlate with psychological distressa dn might further reduce the impact of burden and perceived burden. The role of medical interview satisfaction was tested by entering it on step 4 . Again the model suggests that it would be correlated with psychological distress and might also reduce the impact of burden and perceived burden. Between them these variables accounted for $72 \%$ of the variance in psychological distress.

Table 3: Correlations and descriptive statistics for study variables

\begin{tabular}{|c|c|c|c|c|c|c|c|c|c|c|}
\hline & Mean (Sd) & 2 & 3 & 4 & 5 & 6 & 7 & 8 & 9 & 10 \\
\hline 1. Burden of care & $21.9(13.4)$ & $.78^{* *}$ & -.00 & $-.37^{* *}$ & $-.21^{* *}$ & $-.16^{* *}$ & -.12 & $-.32^{* *}$ & $.43^{* *}$ & $.21^{* *}$ \\
\hline 2. Perceived burden & $12.2(4.4)$ & & -.10 & $-.31^{* *}$ & $-.31^{* *}$ & $-.23^{* *}$ & -.09 & $-.24^{* *}$ & $.54^{* *}$ & $.19^{* *}$ \\
\hline 3. Support from family & 15.5 (4.2) & & & $.26^{* *}$ & $.23^{* *}$ & $.12^{*}$ & .13 & $.23^{* *}$ & -.10 & $-.12^{*}$ \\
\hline 4. Support from friends & $15.7(5.0)$ & & & & $.20^{* *}$ & $.36^{* *}$ & $.32^{*}$ & $.71^{* *}$ & $-.24^{* *}$ & $-.34^{* *}$ \\
\hline 5. MISS & $4.5(0.8)$ & & & & & .08 & .07 & $.15^{*}$ & $-.14^{*}$ & $-.23^{* *}$ \\
\hline 6. Self-efficacy & $2.5(0.8)$ & & & & & & $.31^{* *}$ & $.26^{* *}$ & $-.26^{* *}$ & $-.51^{* *}$ \\
\hline 7. Resilience & $2.9(0.8)$ & & & & & & & $.25^{* *}$ & $-.24^{* *}$ & $-.50^{* *}$ \\
\hline 8. Optimism & $11.1(2.2)$ & & & & & & & & $-.12^{*}$ & $-.26^{* *}$ \\
\hline 9. Perceived stress & $19.4(4.5)$ & & & & & & & & & $.37^{* *}$ \\
\hline 10. Psychological distress & 15.6 (7.9) & & & & & & & & & \\
\hline
\end{tabular}

${ }^{*} p<.05$ (2-tailed); ${ }^{* *} p<.01$ (2-tailed);

Table 4: Hierarchical multiple regression of psychological health onto study variables

\begin{tabular}{|c|c|c|c|c|c|c|c|c|c|c|c|c|}
\hline \multirow{2}{*}{ Dependent variable $^{* *}$} & \multicolumn{3}{|c|}{ Step 1} & \multicolumn{3}{|c|}{ Step 2} & \multicolumn{3}{|c|}{ Step 3} & \multicolumn{3}{|c|}{ Step 4} \\
\hline & B & SEB & $\beta$ & B & SEB & $\beta$ & B & SEB & $\beta$ & B & SEB & $\beta$ \\
\hline Burden & 2.07 & . 40 & $.33^{\#}$ & .40 & .29 & .06 & .59 & .27 & $.10^{*}$ & .64 & .27 & $.10^{*}$ \\
\hline Perceived burden & 1.56 & .45 & $.22^{\#}$ & -.04 & .32 & -.01 & -.28 & .29 & -.04 & -.40 & .29 & -.06 \\
\hline Resilience & & & & -2.87 & .50 & $-.31^{\#}$ & -2.10 & .47 & $-.23^{\#}$ & -1.63 & .48 & $-.18^{\#}$ \\
\hline Self-efficacy & & & & -.36 & .07 & $-.29^{\#}$ & -.19 & .07 & $-.15^{\S}$ & -.20 & .07 & $-.16^{\S}$ \\
\hline Optimism & & & & -1.33 & .25 & $-.28^{\#}$ & -.87 & .25 & $-.18^{\#}$ & -.63 & .25 & $-.13^{\S}$ \\
\hline Family support & & & & & & & -.45 & .08 & $-.32^{\#}$ & -.32 & .09 & $-.23^{\#}$ \\
\hline Friend support & & & & & & & -.29 & .07 & $-.14^{\S}$ & -.25 & .07 & $-.12^{\S}$ \\
\hline MISS & & & & & & & & & & -.63 & .15 & $-.22^{\#}$ \\
\hline $\mathrm{R}^{2}$ Change & $.24^{\#}$ & & & $.41^{\#}$ & & & $.05^{\#}$ & & & $.02^{\S}$ & & \\
\hline Overall R ${ }^{2}$ & $.72^{\#}$ & & & & & & & & & & & \\
\hline
\end{tabular}

" Dependent variable $=$ Psychological distress ${ }^{*} p<.05 ;{ }^{\mathrm{s}} p<.01 ; "$ p $p .001$

Burden and perceived burden accounted for $24 \%$ of the variance on step 1 . When resilience, self-efficacy and optimism were entered in step 2 they added a further $41 \%$ to the variance explained. The addition of these three psychological variables rendered the correlation between both burden and perceived burden and psychological distress to nonsignificance and reduced the beta value for each from $\beta=.33$ to $\beta$ $=.06$ and $\beta=.22$ to $\beta=-.01$ respectively. Adding support from family and friends on step 3 added a further $5 \%$ to the variance explained and reduced the correlation between re- silience $(\beta=-.31$ to $\beta=-.23)$, self-efficacy $(\beta=-.29$ to $\beta$ $=-.15)$, and optimism $(\beta=-.28$ to $\beta=-.18)$, and psychological distress. The addition of satisfaction with medical care on step 4 explained a further $2 \%$ of the variance and reduced the correlation between family support ( $\beta=-.32$ to $\beta=-.23$ ), and friend support $(\beta=-.14$ to $\beta=-.12)$, and psychological distress.

The final stage in analysis reran the HMRA substituting perceived stress for psychological distress as the dependent variable (see Table 5). This time the overall model ac- 
counted for $71 \%$ of the variance in perceived stress. Burden and perceived burden accounted for $28 \%$ of the variance on step 1 . When resilience, self-efficacy and optimism were entered in step 2 they added a further $37 \%$ to the variance explained. The addition of these three psychological variables rendered the correlation between both burden and perceived burden and psychological distress to nonsignificance and reduced the beta value for each from $\beta=.31$ to $\beta=$ .05 and $\beta=.29$ to $\beta=-.08$ respectively. Adding support from family and friends on step 3 added a further $5 \%$ to the variance explained and reduced the correlation between resilience $(\beta=-.26$ to $\beta=-.16)$, self-efficacy $(\beta=-.33$ to $\beta$ $=-.18)$, and optimism $(\beta=-.25$ to $\beta=-.13)$, and psychological distress. However only family support produced a significant beta. The addition of satisfaction with medical care on step 4 explained a further $1 \%$ of the variance and reduced the correlation between family support $(\beta=-.40$ to $\beta=-.32)$, and friend support $(\beta=-.05$ to $\beta=-.04)$, and psychological distress.

Table 5: Hierarchical multiple regression of perceived stress onto study variables

\begin{tabular}{|c|c|c|c|c|c|c|c|c|c|c|c|c|}
\hline \multirow{2}{*}{ Dependent variable ${ }^{\#}$} & \multicolumn{3}{|c|}{ Step 1} & \multicolumn{3}{|c|}{ Step 2} & \multicolumn{3}{|c|}{ Step 3} & \multicolumn{3}{|c|}{ Step 4} \\
\hline & B & SEB & $\beta$ & B & SEB & $\beta$ & B & SEB & $\beta$ & B & SEB & $\beta$ \\
\hline Burden & .46 & .09 & $.31^{\S}$ & .08 & .07 & .05 & .16 & .07 & $.11^{* *}$ & .17 & .06 & $.12^{* *}$ \\
\hline Perceived burden & .49 & .10 & $.29^{\S}$ & .13 & .08 & .08 & .05 & .07 & .03 & .03 & .07 & .02 \\
\hline Resilience & & & & -.57 & .12 & $-.26^{\S}$ & -.35 & .11 & $-.16^{* *}$ & -.25 & .12 & $-.11^{*}$ \\
\hline Self-efficacy & & & & -.10 & .02 & $-.33^{\S}$ & -.05 & .02 & $-.18^{\S}$ & -.05 & .02 & $-.18^{\S}$ \\
\hline Optimism & & & & -.28 & .06 & $-.25^{\S}$ & -.14 & .06 & $-.13^{* *}$ & -.09 & .06 & -.08 \\
\hline Family support & & & & & & & -.14 & .02 & $-.40^{\S}$ & -.11 & .02 & $-.32^{\S}$ \\
\hline Friend support & & & & & & & -.02 & .02 & -.05 & -.02 & .02 & -.04 \\
\hline MISS & & & & & & & & & & -.12 & .04 & $-.18^{\S}$ \\
\hline $\mathrm{R}^{2}$ Change & $.28^{\S}$ & & & $.37^{\S}$ & & & $.05^{\S}$ & & & $.01^{* *}$ & & \\
\hline Overall $\mathrm{R}^{2}$ & $.71^{\S}$ & & & & & & & & & & & \\
\hline
\end{tabular}

${ }^{\#}$ Perceived Stress; ${ }^{*} p<.05 ;{ }^{* *} p<.01 ;{ }^{\S} p<.001$

\section{Discussion}

Before discussing the specific findings in relation to the aims and hypothesis it is important to state that a large percentage $(64.7 \%)$ of the sample, were exhibiting clinical levels of distress. This compares to figures of around $38 \%$ for women of a similar age in general population samples. ${ }^{[36]}$ While the prevalence in this study is high, it is not unusual as other studies show caregiver clinical distress rates of up to $62 \%$. ${ }^{[37]}$ The GHQ-12 is used as an epidemiological screening tool measuring depression, anxiety and somatisation. Scoring above the clinical cut off indicates a potential clinical level of distress. However, it is only indicative and for many it may reflect high scores on a few items, e.g. difficulty sleeping, and may not reflect a clinical disorder. What it does highlight is that a large number of caregivers should be screened and offered mental health interventions if necessary.

As with previous research both perceived burden and actual burden of care are related to elevated levels of perceived stress and psychological distress. ${ }^{[1,5-7]}$ Both are also negatively correlated with support from friends but not related to support from family. This may help to explain the equivocal findings on the impact of social support on family caregivers. ${ }^{[38]}$ Previous studies have tended to focus on social support in general rather than distinguishing between support from family and support from friends. As a family caregiver the support from family is likely to be reduced as the responsibility is to give support rather than receive it. Indeed well-meaning family may increase the burden on caregivers through attempts to support. ${ }^{[38]}$ Having supportive friends in such circumstances may enable caregivers to escape their burden for periods of time. The findings here would support the conclusion that "social support resources should be tailored to the caregiver's support needs and include assessment on the type of support to be offered". [38] This can also be linked to the negative correlation between satisfaction with medical care and burden as positive relations with health care professionals provides an important support net for family caregivers as well as their patients.

Self-efficacy, optimism and resilience are negatively related to both burden and stress suggesting that they might mediate the relationship and providing a basis for testing the resource model proposed. The utility of considering the impact of caregiving in terms of a resource model of stress is illustrated from the HMRA which provides general support for the model in regard to both the outcome variables of psychological distress and perceived stress. The ability of both psychological and social resources, as well as satisfaction with medical care, to explain significant amounts of variance in the outcome variables, and their ability to reduce the relationship with burden and perceived burden, suggests potential mediating effects. The success of the resource model of stress in this data points to possible interventions. The need to apply a resource building approach in supporting 
family carers is indicated; a focus on increasing social support, particularly support based on needs assessment, alongside the development of resilience should improve the quality of life for caregivers and should go well beyond just enabling them to survive. Improving the relationship between health and medical care services and caregivers is empirically supported in this study as one aspect of a more positive approach to providing support. There is a growing literature on resilience building interventions which can be adapted to caregiver needs. ${ }^{[39]}$

\section{Limitations and future directions}

The main limitation of the study was that it was cross sectional and cannot be generalised to males. A longitudinal approach would enable more definite conclusions to be drawn and provide the opportunity for more causal inferences. One conclusion from this and previous research, ${ }^{[38]}$ is that support services need to be targeted to needs of caregivers. In order to address this in future the inclusion of qualitative interviews either as part of a mixed methods approach or as a separate study would allow more in depth analysis of the experiences of care givers. The current sample were all female because very few males responded but there is a need to include males and in the case of children to include both parents. This would require more targeted sampling. On the other hand most carers are female and as indicated the stress of caregiving is generally more severe for them. ${ }^{[6,7]}$ There seems to be general agreement across the UK, Europe and the US that over one third of caregivers are female. ${ }^{[40,41]}$ One could argue that understanding the impact and related variables in a female sample will give a better steer to supporting the work they do.

\section{Conclusion and recommendations}

Given the important role played by caregivers in health care delivery, understanding the variables that might be targeted in enabling them to avoid the negative health consequences of caregiving is essential. This study provides support for a resource model of stress and the potential utility of resource building interventions. The findings suggest that focusing on increasing social support and on developing psychological resources such as resilience skills, could make the caregiving role more manageable. ${ }^{[39]}$

The inverse relationships between demand and psychological and social resources reminds us that we still need to focus on ways to reduce the care load for caregivers as higher levels of demand correspond with lower levels of resources. In cross-sectional data we cannot establish causality though previous research would suggest that high levels of stress can reduce the individual's coping resources. The correlation between demand and psychological distress in this sample confirm that caregiving is a high stress occupation. Support services must continue to find ways of reducing or removing the load from family caregivers where possible. However where it is inevitable that family members shoulder the burden of care there is a need to ensure that the negative health consequences for them are prevented or reduced.

There are a growing number of positive psychology interventions aimed at building resilience and empowering individuals which can be drawn on to help caregivers. ${ }^{[39]}$ This is a move away from a treatment approach which is applied when caregivers become ill themselves, and the current study provides some support for such a move. The main clinical implication is that support services need to engage more in prevention and early intervention with caregivers.

In addition the finding that satisfaction with medical care mediates the stressful impact of caregiving points to the importance of positive experience of health care services for caregivers and suggests that this may be a fruitful way to improve their quality of life. It is very widely known that patient focused care and effective communication between health professionals and patients not only improves adherence to medication but also aids recovery and rehabilitation. ${ }^{[18,19]}$ Where recovery is not a potential outcome, satisfaction with health care enables patients to have a better quality of life. ${ }^{[19]}$ What this study suggests is that what works for patients may also work for caregivers.

\section{References}

[1] Savage S., Bailey S.. The impact of caring on caregivers' mental health: a review of the literature. Australian Health Review. 2004; 27(1): 103-109. http://dx.doi.org/10.1071/AH042710111

[2] Cassidy T. Benefit finding through caring: The cancer caregiver experience. Psychology \& Health. 2012. http://dx.doi.org/10. 1080/08870446.2012.717623

[3] Lazarus R. S.. From psychological stress to the emotions: A history of changing outlooks. Annual Review of Psychology. 1993; 44: 1-21. PMid:8434890. http://dx.doi.org/10.1146/annur ev.ps.44.020193.000245
[4] Cassidy T. Stress, coping, resilience, and health. In T. J. Devonport (Ed). Managing Stress: From Theory to Application. Hauppauge NY. Nova Science Publishers, Inc; 2011.

[5] Dumont S., Turgeon J., Allard P., Gagnon P., Charbonneau C., Vezina L. Caring for a loved one with advanced cancer: determinants of psychological distress in family caregivers. Journal of Palliative Medicine. 2006; 9(4): 912-921. PMid:16910806. http: //dx.doi.org/10.1089/jpm.2006.9.912

[6] Given B, Wyatt G, Given C, et al. Burden and depression among caregivers of patients with cancer at the end of life. Oncology Nursing Forum. 2004; (6): 1105-1117. PMid:15547633. http://dx.d oi.org/10.1188/04.0NF.1105-1117

[7] Pitceathly C, Maguire P. The psychological impact of cancer on pa- 
tients' partners and other key relatives: a review. European Journal of Cancer. 2003; 39: 1517-1524. http://dx.doi.org/10.1016 /S0959-8049(03) 00309-5

[8] Stenberg U, Ruland CM, Miaskowski C. Review of the literature on effects of caring for a patient with cancer. Psycho-Oncology. 2010; 19: 1013-1025. PMid:20014159. http://dx.doi.org/10.1002 /pon. 1670

[9] Swore Fletcher B. A., Dodd M. J., Schumacher K. L., Miaskowski C. Symptom experience of family caregivers of patients with cancer. Oncology Nursing Forum. 2008; 35(2): 23-44. PMid:19405245. http://dx.doi.org/10.1188/08. ONF.E23-E44

[10] Grunfeld E, Coyle D, Whelan T, et al. Family caregiver burden: results of a longitudinal study of breast cancer patients and their principal caregivers. CMAJ. 2004; 170: 1795-1801. http://dx.doi .org/10.1503/cmaj. 1031205

[11] Seligman MEP. Positive Health. Applied Psychology: An International Review. 2008; 57: 3-18. http://dx.doi.org/10.1111/j .1464-0597.2008.00351.x

[12] Gaugler J. E., Kane R. L., Newcomer R. Resilience and transitions from dementia caregiving. J Gerontol B Psychol Sci Soc Sci. 2007 Jan; 62(1): 38-44. http://dx.doi .org/10.1093/geronb/62.1 .P38

[13] Zeiss A. M., Gallagher-Thompson D., Lovett S., Rose J., McKibbin C. Self-Efficacy as a Mediator of Caregiver Coping: Development and Testing of an Assessment Model. Journal of Clinical Geropsychology. 1999 July; 5(3): 221-230. http://dx.doi.org/10.10 23/A: 1022955817074

[14] Fotiadou M., Barlow J. H., Powell L.A., Langton H. Optimism and psychological well-being among parents of children with cancer: an exploratory study. Psycho-Oncology. (2008); 17(4): 401-409. PMid:17828706. http://dx.doi.org/10.1002/pon.1257

[15] Chii Jun Chiou C. J., Chang H-Y, Chen P., Wanga H. H. Social support and caregiving circumstances as predictors of caregiver burden in Taiwan. Archives of Gerontology and Geriatrics. 2009; 48: 419-424. PMid:18602706. http://dx.doi.org/10.1016/j .archger.2008.04.001

[16] Neenan M. Developing Resilience: A Cognitive Behavioural Approach. Hove: Routledge; 2009.

[17] Walsh F. Strenthening Family Resilience. 2nd ed. New York: Guilford Press; 2006

[18] Davidson R., Mills M.E. Cancer patients' satisfaction with communication, information and quality of care in a UK region. European Journal of Cancer Care. 2005; 14: 83-90. PMid:15698390. http://dx.doi.org/10.1111/j.1365-2354.2005.00530.x

[19] Ong LML, M.R.M. Visser, MRM F.B. Lammes, FB, De Haes JCJM. Doctor-Patient communication and cancer patients' quality of life and satisfaction. Patient Education and Counseling. 2000; 41: 145156.

[20] Gilbar O, Zusman A. The correlation between coping strategies, doctor-patient/spouse relationships and psychological distress among women cancer patients and their spouses. Psycho-Oncology. 2007; 16: 1010-1018. PMid:17345559. http://dx.doi.org/10. 1002/pon. 1168

[21] Weinberg D. B., Lusenhop R. W., Gittell J. H., Kautz C. M. Coordination between formal providers and informal caregivers. Health Care Manage Rev. 2007; 32(2): 140-149. PMid:17438397. http: //dx.doi.org/10.1097/01.HMR.0000267790.24933.4c

[22] Early L., Cushway D., Cassidy T. Perceived stress in young carers: Development of a measure Journal of Child and Family Studies. 2006; 15(2): 165-176. http://dx.doi.org/10.1007/s1082 6-005-9011-z

[23] Cassidy T. Benefit finding through caring: The cancer caregiver experience. Psychology \& Health. 2012. http://dx.doi.org/10. $1080 / 08870446.2012 .717623$
[24] Cassidy T., Giles M. Further exploration of the Young Carers Perceived Stress Scale: Identifying a benefit-finding dimension. B J of Health Psychology. 2012. http://dx.doi.org/10.1111/bjhp. 12017

[25] Cohen S., Williamson G. Perceived stress in a probability sample of the U.S. In S. Spacapam \& S. Oskamp (Eds.), The social psychology of health: Claremont Symposium on Applied Social Psychology. Newbury Park, CA: Sage. 1988.

[26] Cohen S., Kamarck T., Mermelstein R. A global measure of perceived stress. Journal of Health and Social Behaviour. 1983; 24: 385-96. PMid:6668417. http://dx.doi.org/10.2307/213 6404

[27] Lazarus R. S., Folkman S. Stress, appraisal and coping. New York: Springer; 1984.

[28] Schwarzer R. Self-efficacy: Thought Control of Action. Washington: Hemisphere; 1992.

[29] Scheier M. F., Carver C. S. Optimism, coping, and health: Assessment and implications of generalised outcome expectancies. Health Psychology. 1985; 4: 219-247. PMid:4029106. http://dx.doi.o $\mathrm{rg} / 10.1037 / 0278-6133.4 .3 .219$

[30] Smith B. W., Dalen J., Wiggins K., Tooley E., Christopher P., Bernard J. The Brief Resilience Scale. Measuring the Ability to Bounce Back. International Journal of Behavioral Medicine. 2008; 15: 194-200. PMid:18696313. http://dx.doi.org/10.1080/1 0705500802222972

[31] Meakin R., Weinman J. The 'Medical Interview Satisfaction Scale' (MISS-21) adapted for British general practice. Family Practice. 2002; 19(3): 257-263. PMid:11978716. http://dx.doi.org/1 $0.1093 /$ fampra/19.3.257

[32] Wolf M. H., Putnam S. M., James A. J., Stiles W. B. The Medical Interview Satisfaction Scale: Development of a scale to measure patient perceptions of physician behaviour. Journal of Behavioural Medicine. 1978; 1: 391-401. PMid:755868. http://dx.doi.org /10.1007/BF00846695

[33] Procidano M. E., Heller K. Measures of perceived social support from friend and from family: Three validation studies. American Journal of Community Psychology. 1983; 11: 1-23. PMid:6837532. http://dx.doi.org/10.1007/BF00898416

[34] Goldberg D. The detection of psychiatric illness by questionnaire. London: OUP; 1972.

[35] Goldberg D. Manual of the General Health Questionnaire. Windsor, United Kingdom: NFER Publishing Company; 1978.

[36] Oliver M. I., Pearson N., Coe N., Gunnell D. Help-seeking behaviour in men and women with common mental health problems: cross-sectional study. British Journal of Psychiatry. 2005; 186: 297301. http://dx.doi.org/10.1192/bjp.186.4.297

[37] Fujinami R., Sun V., Zachariah F., Uman G., Grant M., Betty Ferrell B. Family caregivers' distress levels related to quality of life, burden, and preparedness. Psycho-Oncology. 2014.

[38] Wittenberg-Lyles E., Washington K., Demiris G., Parker Oliver D., Sara Shaunfield S. Understanding Social Support Burden Among Family Caregivers. Health Communication. 2014; 29(9): 901-910. http://dx.doi.org/10.1080/10410236.2013.815111

[39] Tedeschi R. G., Kilmer R. P. Assessing Strengths, Resilience, and Growth to Guide Clinical Interventions. Professional Psychology: Research and Practice. 2005; 36(3): 230-237. http://dx.doi.o $\mathrm{rg} / 10.1037 / 0735-7028.36 .3 .230$

[40] The National Alliance for Caregiving and AARP (2009), Caregiving in the U.S. National Alliance for Caregiving. Washington, DC. Updated: November 2012. Available from: https://caregiver. org/selected-caregiver-statistics

[41] OECD. The impact of caring on family carers. In Help Wanted? Providing and Paying for Long-Term Care. 2011. 